any new information. I read with interest that associations exist for such parents but this, to my mind, emphasizes the hunger for contact with others and the sense of loneliness felt.

Since the vast majority of cases occur in the home the collection, collation, and even computerization of this information must start from the parent. I am convinced that somewhere in the detailed case histories there are clues, but in the meantime innocent factors come under suspicion. I would not wish to belittle the valuable work already being done, but I believe a wealth of information is being neglected and the time has come for a drastic approach to this problem.-I am, etc.,

Dry Drayton,

IRWIN PeCK

\section{Papillary Necrosis in a Transplanted Kidney}

SIR,-The aetiology of renal papillary necrosis is a more complex problem than $\mathrm{Dr}$. R. P. S. Edmonson and others (26 February, p. 547) appear to indicate. Histological changes, especially those recorded some time after the primary event, are not in general a reliable guide either to the cause of a lesion, or to the state of the blood flow at the time it occurred. Helderman and Klavins ${ }^{1}$ considered that their in vitro experiments demonstrated the cytotoxic effects of complement activated human serum upon rat renal medulla; this had previously been shown in vivo. $^{2}$ In experimental renal papillary necrosis produced by ethylene imine ${ }^{3}$ damage to all components of the medulla precedes demonstrable alterations in medullary blood flow. In this model we have now shown severe damage to all medullary cells within one hour of intravenous administration of the toxic compound.

It is only in the experimental model that the evolution of renal medullary necrosis can be studied in detailed sequence, and these indicate the existence of cytotoxic factors. Certainly, caution is needed in applying experimental observations to clinical conditions, but equal care needs to be exercised in postulating a common mechanism for the medullary lesions of sickle-cell anaemia and ureteric obstruction and the complete papillary necrosis complicating severe pyelonephritis, diabetes, and analgesic renal disease.-We are, etc.,

C. C. FUNDER

C. R. GREEN

K. M. HAM

J. D. TANGE

Department of Pathology,

University of Melbout

1 Helderman. J. H.. and Klavins, J. V., Archives
of Pathology, 1970 89. 453.
2 Liungavist, A., Osvaldo-Decima, L.. and Richard-
son, J Laboratory Investigation, 1967. 17 447.
3 Ham, K. K. N. and Tanre. J., D. Australasian
Annals of Medicine, 1969, 18, 199.

Pulmonary Oedema Related to Coronary Angiography

SiR,-Having encountered two cases of pulmonary oedema related to coronary angiography with left ventriculography I feel this should be considered a complication of the procedure. Your leading article (3 April 1971, p. 3) on "Hazards of Coronary Arteriography" lists the various hazards but does not include pulmonary oedema.
A 37-year-old white male had angina pectoris for two years with recent exacerbation but no history of cardiac decompensation. The E.C.G. showed transient ischaemic changes with paip. $\mathrm{He}$ was treated with nitroglycerin as needed and propranolol $20 \mathrm{mg}$ orally four times daily, which he received till the evening before coronary angiography. A bilateral selective coronary angiogram by Judkin's technique was performed. Three injections each of $5-6 \mathrm{ml}$ of $76 \%$ renograffin were made into each coronary artery for three views. A left ventriculogram was made with the injector. His left ventricular end-diastolic pressure was $12-14 \mathrm{~mm} \mathrm{Hg}$ before the ventriculogram, but after it rose to 22-25 $\mathrm{mm} \mathrm{Hg}$. Immediately after the procedure the patient developed cough and dyspnoea and became orthopnoeic. The situation was immediately recognized as left ventricular decompensation and treated with oxygen inhalation, frusemide $80 \mathrm{mg}$, and digoxin $0.5 \mathrm{mg}$ given parenterally with good result. His coronary angiogram showed $70 \%$ obstruction of the main left coronary artery, $50 \%$ obstruction of the middle third of the posterior circumflex artery, and almost total obstruction of the right coronary artery. The left ventriculogram showed normal contractility.

The second patient was a 69-year-old male diabetic who had had angina pectoris for two years. During the investigation he became orthopnoeic and hypotensive and started to cough. Crepitations were heard in both lungs and accentuated pulmonary second sound. There was an improvement when oxygen, morphine, digoxin, and frusemide were administered, but he died the following day.

Necropsy confirmed the radiological finding of $70 \%$ stenosis of the main left trunk and the origin of anterior descending branch. The right coronary artery showed atherosclerosis without obstruction. There was severe pulmonary oedema. In both cases pulmonary oedema seems related to the procedure of coronary angiography/left ventriculography. It has been shown that left ventricular filling pressure rises during coronary angiography ${ }^{1}$ and angiocardiography. ${ }^{2}$ The degree of rise of left ventricular filling pressure is directly related to the severity of coronary artery disease. Contrast agents exert negative inotropic effects on myocardium, and this seems to be the most likely cause here. Propranolol might be another contributing factor by its negative inotropic effect.

It is concluded that any agent having a negative inotropic effect should be withheld as early as possible before coronary angiography and great caution is mandatory in patients who are suspected of having severe coronary artery disease on the basis of clinical evaluation. However, it is not possible to assess the severity of coronary artery disease in most cases without coronary angiogram and left ventriculogram. Monitoring of the left ventricular end diastolic pressure, at least in cases suspected of severe disease, may be worthwhile.-I am, etc.,

Columbus,

1 Gensini. G. G., Dubiel, J., Huntington, P. P., and Kelly, A. E, American fournal of Cardio2 Brown, A. K., Epstein, E. J., Coulshed, N., Clarke, J. M., and Do

\section{Prostaglandins and Resistance to} $\beta$-Adrenoceptor Stimulants

SIR,-We were most interested in Dr. Anne U. Tothill's suggestions (11 March, p. 689) that the release of prostaglandins may be particularly responsible for the resistance of human bronchial muscle to $\beta$-adrenoceptor stimulants, and that this resistance might be overcome by treatment with certain analgesics.

The effects of the prostaglandins on bronchial smooth muscle depend on the individual prostaglandins involved. Those of the $\mathrm{E}$ series relax bronchial muscle, and both prostaglandins $\mathrm{E}_{1}$ and $\mathrm{E}_{2}\left(\mathrm{PGE}_{1}\right.$ and $\left.\mathrm{PGE}_{2}\right)$ are bronchodilators in asthmatic subjects. ${ }^{12}$ On the other hand, prostaglandins of the $F$ series and particularly $\mathrm{PGF}_{2} \alpha$ are potent bronchoconstrictors in a number of species, and in experiments in healthy male volunteers we have recently shown that the inhalation of $\mathrm{PGF}_{2} \alpha$ results in an increase in airways resistance and a fall in specific airways conductance. In these circumstances the sensitivity of the bronchial muscle is not diminished; in fact, the inhalation of isoprenaline readily reverses the bronchoconstriction. On this evidence it therefore seems unlikely that prostaglandin release is responsible for resistance to $\beta$-adrenodeptor stimulants.

Although Vane $^{3}$ has demonstrated that aspirin and certain non-steroidal anti-inflammatory drugs inhibit prostaglandin synthesis, and Sweatman and Collier ${ }^{45}$ find these agents effective in preventing the responses of isolated human bronchial muscle to $\mathrm{PGF}_{2} \alpha$, we have been unable to demonstrate, in preliminary experiments, any suppression of the bronchoconstrictor action of inhaled $\mathrm{PGF}_{2} \alpha$ in healthy volunteers previously treated with flufenamic acid, or any change in airways resistance in asthmatic subjects after ingestion of large doses of indomethacin. Indeed, some asthmatics may be adversely affected by treatment with analgesics and anti-inflammatory drugs ${ }^{6}$ and we would not, at this stage, recommend this procedure.-We are, etc.,

Chest Unit Department of Medicine,

A. P. SMITH King's College Hospital, \section{F. CUTHB
Department of Pharmacology and Therapeutics,
London Hospital Medical College, \\ London E.1}

Cuthbert, M. F., British Medical fournal, 1969 $4,723$.

Cuthbert, M. F., Proceedings of the Royal Society 3 Vane, J. R., Nature New Biology, 1971, 231, 4 Sweatman, W. J. F. and Collier H. O. J., Na ure (Lond), 1968, 217, t9.
5 Collier, H. O. J and Sweatman, W. J. F., Na:ure (Lond), 1968, 219, 864.
Smith, A. P., British Medical fournal, 1971,
2, 494.

\section{Reversible Airways Obstruction}

SIR,-The paper by Dr. R. J. Alliott and others (26 February, p. 539) is of great interest to me as I have recently reported a similar comparative trial of salbutamol and isoprenaline/phenylephrine with slightly differing results.

The patients I studied were 11 chronic bronchitics with reversibility of airways obstruction (increase in $\mathrm{FEV}_{1} \geqslant 20 \%$ after bronchodilator). Baseline measurements were always made after the use of an aerosol containing inert propellant only, thus compensating for any placebo effect.

The Table shows mean changes ( \pm S.E.) and probability values ( $t$ test) for $F E V_{1}$, $\mathrm{PaCO}_{2}, \mathrm{PaO}_{2}, \mathrm{VD} / \mathrm{VE}$, and cardiac output (QT). Individual results were published in the previously mentioned paper. 